\title{
Nurse staffing, patient turnover and safety climate and their association with in-patient falls and injurious falls on medical acute care units: a cross-sectional study
}

\author{
Therese Hirsbrunner ${ }^{1}$, Kris Denhaerynck ${ }^{2}$, Katharina Fierz ${ }^{2}$, Koen Milisen ${ }^{3,4}$, Rene Schwendimann*2 \\ ${ }^{1}$ Spital Solothurn, Switzerland \\ ${ }^{2}$ University of Basel, Switzerland \\ ${ }^{3}$ Department of Public Health and Primary Care, Health Services and Nursing Research, KU Leuven, Leuven, Belgium \\ ${ }^{4}$ Department of Geriatric Medicine, University Hospitals Leuven, Leuven, Belgium
}

Received: February 12, 2015

DOI: $10.5430 /$ jha.v4n3p54
Accepted: April 3, 2015

Online Published: April 15, 2015

\begin{abstract}
Objective: Falls and related injuries remain a considerable health risk for in-patients. Numerous studies link falls with nurse staffing levels, but the results are inconsistent. The purpose of this study was to explore the associations between fall prevalence and injurious falls on medical wards and three unit-level system factors: daily nurse staffing, patient turnover, and safety climate. Methods: Using a cross-sectional design, we conducted a secondary data analysis of data from the Patient Safety and Falls Project. Five medical units in a Swiss university hospital were included, resulting in a data set of 949 days, with daily measures of nurse staffing, patient turnover and falls. The safety climate was measured using a subscale of the Safety Attitudes Questionnaire and analyzed at the unit level including data from 154 nurses. Robust multivariate logistic regression was used to explore nurse staffing, patient turnover, and safety climate's associations with in-patient falls and fall injuries.

Results: After controlling for patient age, length of stay and nursing fulltime equivalents, registered nurse experience showed a significant negative relationship with falls $(\mathrm{OR}=.83, p<.0001)$. Patient turnover and safety climate were not significantly associated to falls or fall injuries.

Conclusions: By linking nurse staffing variables to in-patient falls and fall injuries, the current study's findings partly confirm those of previous research. Further investigation will be necessary to isolate key factors influencing the association at the unit level between safety climate and in-patient falls.
\end{abstract}

Key Words: Nurse staffing, Patient turnover, Safety climate, In-patient falls, Injurious falls

\section{INTRODUCTION}

Morbidity, mortality and costs resulting from hospital inpatient falls are considerable. An analysis of 6,100 units in 1,263 US hospitals over a period of 27 months showed an overall fall rate of 3.56 per 1,000 bed days, with $26.1 \%$ of these falls leading to injury. ${ }^{[1]}$ Murray, Cameron \& Cumming ${ }^{[2]}$ showed that $28 \%$ of patients who sustained proximal femoral fractures due to falls while hospitalized died. Furthermore, $33 \%$ of patients who suffered falls in hospitals were dischared to long-term care facilities. ${ }^{[2]}$ Brand \& Sun-

\footnotetext{
*Correspondence: Rene Schwendimann; Email: rene.schwendimann@ unibas.ch; Address: Institute of Nursing Science, Bernoullistrasse 28, 4056 Basel, Switzerland.
} 
dararajan $^{[3]}$ observed that lengths of stay were far longer for patients who fell in hospital than for those without falls (respective medians: 19 days versus 5 days, $p<.0001$ ). In a review on the economic burden of falls in old age, costs for fall-related hospitalizations ranged from 5,654 to 42,840 US dollars. ${ }^{[4]}$

Systematic reviews and guidelines provide evidence on fall prevention interventions, ${ }^{[5,6]}$ but the effects of hospital fall prevention programs fade over extended periods. ${ }^{[7-11]}$

In a survey of 4,412 nurses and nurse assistants in eleven acute care hospitals, Kalisch, Tschannen and Hee Lee ${ }^{[12]}$ found a significant association between omitted nursing care and more falls. A previous study showed that the number of nurse hours per patient day was a significant predictor of missed care. ${ }^{[13]}$ One of the most commonly missed care elements was ambulation - a core element of fall prevention. Several studies have associated lower patient-to-nurse ratios and skill mixes that include higher proportions of registered nurses with lower fall rates; ${ }^{[14-16]}$ others have showed no such relationship. ${ }^{[17-19]}$ These findings' lack of consistency may relate to their studies' levels of analysis, i.e., hospital, unit, day or shift, while daily or shift variability may be muted at the unit level when data are aggregated on an annual basis or at the hospital level. ${ }^{[20]}$

In addition, working conditions and processes in a hospital or unit may hinder nurses' ability to prevent falls. ${ }^{[21]}$ In a crosssectional study, Myny et al. ${ }^{[22]}$ identified work interruptions and high patient turnover rates as the nursing workload's most important and measurable fall-related factors. The current trend towards shortening hospital stays can lead to faster patient turnover, complicating nursing demands and increasing workloads. ${ }^{[23-25]}$ Patient turnover has also been linked to such outcomes as failure-to-rescue and mortality. ${ }^{[26,27]}$

Another possible unit-level factor is safety climate. Sexton, et al. ${ }^{[28]}$ defines the safety climate as the consensus of shared perceptions regarding patient safety norms and behaviors by frontline care workers in a given clinical area. A strong safety climate supports the adherence to safe work practices and mitigates the effect of factors that hinder safe work behaviors. ${ }^{[29]}$ Several studies indicate that a unit's safety climate is a predictor of patient outcomes, but results vary. For example, whereas Vogus \& Sutcliff ${ }^{[30]}$ and Taylor, et al. ${ }^{[31]}$ negatively correlated safety climate with in-patient falls, Ausserhofer et $a l .{ }^{[32]}$ could not reproduce these findings.

\subsection{Conceptual framework}

We developed our conceptual framework with the variables under study based on previous research. ${ }^{[29,32,33]}$ As described above, patient turnover and safety climate are our

Published by Sciedu Press main context factors, along with length of stay, patient age and nursing care time per patient, as a proxy for patient complexity. As structural factors, we used nurse staffing and nurse characteristics variables. In-patient falls and falls with injuries are measured as outcome variables.

\subsection{Study objectives}

The objectives of the study were: (1) to determine daily nurse staffing levels, patient turnover rates, safety climate and the daily incidences of falls and injurious falls on medical wards, (2) to explore whether daily nurse staffing levels, daily patient turnover rates and safety climate are related to the frequencies of in-patient falls and injurious falls.

\section{MethodS}

\subsection{Design}

This paper presents a secondary analysis of data from the "Patient Safety and Falls" project (PASAF), using a crosssectional design.

\subsection{Setting and sample}

Five medical units in a university hospital in Switzerland were included. One medical unit specialized in acute geriatrics. Nurse staffing level and patient data, including admissions, discharges, and falls, were collected from 1st November 2009 to 30th April 2010 from administrative records. All patients 18 years of age or older who were hospitalized for at least 24 hours during the study period were included. Registered nurses (RN) and nurse assistants (NA) were included as nursing staff, but nurse managers were excluded. For the safety climate measurement in September 2009, RNs were eligible if they met the following inclusion criteria: direct involvement in patient care, employment for at least one month at an employment level of at least $30 \%$ on the tested ward. NA's were excluded from the safety climate survey.

\subsection{Variables and measures \\ 2.3.1 Context variables}

The patient turnover rate was calculated by dividing the sum of daily admissions and discharges by the total number of patients per day in each unit, thus obtaining an index between 0 and 1, with a higher index indicating a higher daily turnover rate. For the safety climate measurement we used the seven-item safety climate subscale of the Safety Attitudes Questionnaire (SAQ) (see Table 1). The SAQ elicits attitudes regarding interventions associated with the caregivers' patient safety improvement behavior. ${ }^{[34,35]}$ Psychometric testing of the instrument and its subscales yielded acceptable to good ratings. ${ }^{[35-37]}$ The safety climate items were scored on a five-point Likert scale ranging from 1 (disagree strongly) to 5 (agree strongly). Patient characteristics were measured 
as age, gender and length of stay in hospital. The nursing fulltime equivalent was considered as a proxy for patient complexity. The nursing time was retrieved from the hospital nursing performance recording system. We presume that the more nurse hours used by a patient the more complex is the state in which he or she is.

Table 1. SAQ items for safety climate ${ }^{[35]}$

I would feel safe being treated in this unit.
In this unit, errors are handled appropriately.
I know the proper channels to direct questions regarding patient
safety in this unit.
I receive appropriate feedback about my performance.
In this unit, it is difficult to discuss errors.
I am encouraged by my colleagues to report any patient safety
concerns I may have.
The culture in this unit makes it easy to learn from the errors of
the others.

\subsubsection{Structure variables}

Nurse staffing was expressed as patient-to-nurse ratio, skill mix, and RN professional experience. For every day and unit, the nurse staffing level was calculated as the ratio of the total number of patients to the total number of nursing staff (patient-to-nurse ratio per day). The nurse skill mix was computed as the percentage of RNs working on the nursing staff every day per unit. The demographic data for registered nurses included age, gender, employment level (\%), experience in profession (years) and experience on the unit (years).

\subsubsection{Outcome variables}

An in-patient fall was defined as an unexpected event in which the patient comes to rest on the ground, floor or lower level while hospitalized. ${ }^{[38]}$ Falls were counted daily as no fall or fall. To allow the linking of a distinct turnover rate and nurse staffing level to each fall, on days with more than one fall, for each additional fall an additional day was added. Three levels were used to differentiate fall severity: no injury, minor injury (e.g., abrasion, contusion) and major injury (e.g., lacerations requiring stitching, fractures, dislocation of joints, intracranial bleeding). Fall data were calculated as falls per 1,000 patient days.

\subsubsection{Data collection and data management}

Administrative data included the number of RN and NA per day as measured by headcounts. Data collection for falls was self-administered by shift nurses over the same period. The electronic nursing performance system used barcodes to record falls and injuries. The safety climate measurement was conducted using questionnaires in September 2009 at the unit level. The questionnaires were distributed within the team meetings. All data were saved anonymously in an electronic database and stored securely.

\subsubsection{Statistical methods}

Descriptive statistics were calculated as appropriate for data distributions and measures of central tendency. To gauge safety climate we calculated proportions of positive safety climate reports for every unit (\% of respondents who agreed slightly and strongly with the items). The associations between contextual and structural factors and falls were analyzed using a logistic regression model, adjusting for the clustering of measurement days within units using General Estimation Equations. In a first step we adjusted for patientto-nurse ratio and skill mix. In 4 further analyses, we sequentially added the following covariates: patient turnover rate, safety climate, patient age, length of stay, FTE per patient. The level of significance was set at $\alpha<.05$. The data were analyzed using IBM SPSS Statistics for Windows, version 20.0 (IBM Inc., Armonk, NY, USA) and SAS version 9.3.1. for Windows (SAS Institute Inc., Cary, NC, USA).

\subsubsection{Ethical aspects}

The PASAF study received approval from the responsible ethical committee in 2009. The completion of the questionnaires was voluntary for all participants and the anonymity of patient and staff data was secured.

\section{RESULTS}

\subsection{Participants}

A sample of 949 hospital days was analyzed, including data from 2,981 in-patients of four medical units and one acute geriatrics unit. All descriptive results are summarized in Table 2. There were significant differences apparent between the patients of the four medical units and the acute geriatrics unit concerning age and length of stay (mean age: $65.8 \mathrm{vs}$. 83.8 years, $p=.000$; mean length of stay: $10.0 v s .19 .1$ days, $p=.000)$. However, the patients did not differ significantly in the mean nursing time per patient stay (7.05 FTE in internal medicine vs. 7.58 FTE in the acute geriatrics unit, $p=.451$ ).

\subsection{Nurse staffing, patient turnover and safety climate}

For all five units, the mean number of patients per RN (patient-to-nurse ratio) was 3.24 per day. The mean number of admissions and discharges per day was 6.25 and the mean patient turnover index was .144. On the acute geriatrics unit, the nurse staffing is more favorable than on the other medical units (mean patient-to-nurse ratio $3.29 \mathrm{vs.} \mathrm{3.05,} p=.000$; mean skill mix $76.3 v s .84 .24, p=.000$ ), and the acute geriatrics unit shows a lower mean patient turnover rate $(.154$ vs. .104, $p=.000$ ). The SAQ questionnaire was completed by 154 nurses. Response rates on the five units ranged from $68 \%-85.4 \%$, and the positive safety climate responses ranged from $60.9 \%-87 \%$. 
Table 2. Units, patients, nurse staffing, patient turnover, safety climate, time of nursing care and falls\#

\begin{tabular}{|c|c|c|}
\hline Variables & Internal medicine units $(n=4)$ & Acute geriatrics unit $(n=1)$ \\
\hline Beds & 152 & 28 \\
\hline Patient days & 35,478 & 5,949 \\
\hline Patients & 2,670 & 311 \\
\hline Age $^{*}$ & $65.82(68 ; 16-104)$ & 83.84 (84; 64-99) \\
\hline Length of stay ${ }^{*}$ & $13.29(10 ; 1-168)$ & $19.13(16 ; 1-134)$ \\
\hline Female (\%) & 42.1 & 60.5 \\
\hline Registered nurses & 135 & 19 \\
\hline Age $^{*}$ & $37.6(35 ; 22-58)$ & $44.09(45 ; 25-60)$ \\
\hline Experience in profession ${ }^{*}$ & $13.4(10.6 ; 0.25-34.5)$ & $15.51(11.13 ; 1.25-40)$ \\
\hline Experience on unit ${ }^{*}$ & $8.7(6.0 ; 0.25-29.25)$ & $13.77(12 ; 0.5-40)$ \\
\hline Female (\%) & 83.5 & 84.2 \\
\hline Patient-to-nurse ratio ${ }^{*}$ & 3.29 (3.21; 1.95-5.9) & $3.05(3 ; 2-4.86)$ \\
\hline Skill mix ${ }^{*} \dagger$ & 76.3 (76.47; 63.16-93.75) & 84.24 (83.33; 72.22-100) \\
\hline Patient turnover rate & $.154(.152 ; 0-.34)$ & $.104(.097 ; 0-.36)$ \\
\hline Safety climate ${ }^{\S}$ & $60.9 \%-87.0 \%$ & $86.8 \%$ \\
\hline Time of nursing care ${ }^{*} \neq$ & 7.05 (3.9; 0.02-204.78) & 7.58 (5.95; 0.32-35-46) \\
\hline Falls & 158 & 32 \\
\hline Falls with injuries & 31 & 9 \\
\hline Fall rate; fall injury rate ${ }^{\varepsilon}$ & $4.45 ; 0.87$ & $5.38 ; 1.51$ \\
\hline
\end{tabular}

Note. ${ }^{*}$ Nurse staffing, patient turnover and falls were measured for every day from 1st November 2009-30th April 2010 ( $\mathrm{n}=949$ days); safety climate measured in November 2009; ${ }^{*}$ mean (median; range); ${ }^{\S}$ proportion of positive safety climate reports; ${ }^{\dagger}$ proportion of registered nurses of whole nursing staff; ${ }^{\ddagger}$ time of nursing care in fulltime equivalents per patient stay; ${ }^{£}$ per 1,000 patient days.

\subsection{Falls}

During the study period, 190 in-patient falls occurred. Twenty percent of falls $(n=39)$ resulted in minor injuries and one fall in a major injury. The overall fall rates and the rate of injurious falls were 4.6 and 0.9 , respectively per 1,000 patient days. We observed a slightly higher fall rate for the acute geriatrics unit than on the medical units (5.38 vs. 4.45 per 1,000 patient days), as well as a higher rate for fall injuries ( 1.51 vs. 0.87 per 1,000 patient days). On average, patients with falls were older than those without (67.3 years $v s .74 .8$ years; $p=.000$ ) and had considerably longer lengths of stay (13.3 days vs. 26.1 days, $p=.000)$. The mean nursing time for patients with falls was significantly higher than for patients without falls (17.3 FTE vs. 6.6 FTE; $p=.000)$. Comparing patients with a fall, there were no significant differences between patients with or without an injury in age, length of stay or nursing time.

\subsection{Association between nurse staffing, patient turnover, safety climate and falls}

In the fully adjusted model (see Table 3), an increase in RN professional experience correlated significantly with a reduction in the odds of falls (OR $=0.83,95 \%$ CI $0.81-0.86)$. Notably, increased proportions of positive safety climate reports were significantly associated with a reduction in the odds of falls (OR $=0.97,95 \%$ CI 0.96-0.99), but this associa- tion disappeared in the fully adjusted model. No significant associations were observed between patient-to-nurse ratio, skill mix, or patient turnover and falls. For fall injuries, a significant association resulted as well for $\mathrm{RN}$ experience, but not in the fully adjusted model. Patient age indicated a significant positive relationship to falls and fall injuries (OR $=1.02,95 \%$ CI $1-1.03$ and $\mathrm{OR}=1.06,95 \% \mathrm{CI} 1.04-1.07)$, but this significant correlation disappeared when adjusting with time of nursing care.

\section{Discussion}

This study explored the unit-level associations between daily nurse staffing, patient turnover, and safety climate and inpatient falls and fall injuries. We observed no association between patient-to-nurse ratios, skill mix and patient turnover rates and in-patient falls. Fall and injury rates were similar to those described in the literature for the medical units, but lower in the geriatrics unit. ${ }^{[1,39]}$ Greater RN professional experience was negatively associated with in-patient falls. Higher proportions of positive safety climate reports were associated with fewer falls, but not when controlled for nursing time. Patient age seems to play an important role for falls and fall injuries, but the association disappears when controlled for the nursing time per patient.

Our findings regarding daily unit level nurse staffing are 
partly in line with existing figures for day- or shift-level measurement on medical units, where higher proportions of RNs, higher total nurse hours and more $\mathrm{RN}$ experience per shift were associated with fewer falls. ${ }^{[14,20]}$ However, whereas Patrician, et al. ${ }^{[20]}$ found that a decreased proportion of RNs per shift led to higher likelihoods both of falls and of falls with injuries, the current study identified no relationship between patient-to-nurse ratio and skill mix and either falls or injurious falls. One possible explanation would be that our sample's combination of low patient-to-nurse ratios and high $\mathrm{RN}$ proportions had a strong protective effect. We suppose that the more favorable ratios in our sample reflect the hospital's academic status. Alongside these findings, the current study's results confirm Krauss, et al.' ${ }^{[40]}$ observation that fall rates were sensitive to patient-to-nurse ratios when one nurse was assigned to seven patients or more, but not when the number of patients was three or less.

Table 3. Regression estimates for falls and fall injuries

\begin{tabular}{|c|c|c|c|c|c|}
\hline Variables & $\begin{array}{l}\text { Model I } \\
\text { OR }(95 \% \text { CI }) p\end{array}$ & $\begin{array}{l}\text { Model II } \\
\text { OR }(95 \% \text { CI }) p\end{array}$ & $\begin{array}{l}\text { Model III } \\
\text { OR }(95 \% \text { CI }) p\end{array}$ & $\begin{array}{l}\text { Model IV } \\
\text { OR }(95 \% \text { CI }) p\end{array}$ & $\begin{array}{l}\text { Model V } \\
\text { OR }(95 \% \text { CI }) p\end{array}$ \\
\hline \multicolumn{6}{|l|}{ Falls } \\
\hline Skill mix & $1.05(0.99-1.02) .64$ & $1.01(0.98-1.03) .64$ & $1.02(0.99-1.05) .08$ & $1.02(0.98-1.05) .37$ & $1.02(0.98-1.05) .37$ \\
\hline RN experience & $\begin{array}{l}1.05(0.78-0.93) \\
.0002\end{array}$ & $\begin{array}{l}0.85(0.77-0.94) \\
.0011\end{array}$ & $\begin{array}{l}0.85(0.77-0.94) \\
.0011\end{array}$ & $0.8(0.74-0.86)<.0001$ & $0.83(0.81-0.86<.0001$ \\
\hline Patient turnover rate & & $1.75(0.13-23.38) .67$ & $1.93(0.16-23.73) .61$ & $2.77(0.24-32.05) .41$ & $2.77(0.24-32.02) .41$ \\
\hline Safety climate & & & 0.98 (0.97-0.99) .01 & $0.97(0.96-0.99)<.0001$ & $1.0(0.96-1.05) .98$ \\
\hline Patient age & & & & $1.02(1-1.03) .04$ & $1.0(0.96-1.04) .99$ \\
\hline Length of stay & & & & $1.06(0.98-1.13) .13$ & - \\
\hline FTE $^{\#}$ per patient & & & & & $1.43(0.9-2.26) .13$ \\
\hline \multicolumn{6}{|l|}{ Fall injuries } \\
\hline Skill mix & $0.99(0.93-1.05) .76$ & $0.98(0.92-1.05) .65$ & $0.96(0.88-1.05) .37$ & $0.95(0.88-1.03) .24$ & $0.95(0.88-1.03) .24$ \\
\hline RN experience & $1.16(1.01-1.32) .04$ & 1.15 (1.02-1.31) .03 & $1.15(1.0-1.33) .05$ & 0.95 (0.83-1.09).48 & $1.03(0.96-1.12) .41$ \\
\hline Patient turnover rate & & $0.13(0-21.84) .44$ & $0.06(0-6.17) .23$ & $0.12(0-9.95) .35$ & $0.12(0-2.3) .35$ \\
\hline Safety climate & & & $1.02(0.99-1.06) .23$ & $1.0(0.97-1.03) .95$ & 1.05 (0.94-1.17). 42 \\
\hline Patient age & & & & $1.06(1.04-1.07)<.0001$ & $1.02(0.95-1.1) .54$ \\
\hline Length of stay & & & & $1.1(0.93-1.13) .27$ & - \\
\hline FTE $^{\#}$ per patient & & & & & $1.88(0.61-5.8) .28$ \\
\hline
\end{tabular}

Note. units $n=5$, observed days $n=949$, falls $n=190$, fall injuries $n=40 ;{ }^{\#}$ FTE = nursing time in full time equivalent.

Evidence relating nurses' professional experience and falls is scarce and with mixed results. ${ }^{[14,41]}$ Throughout our sample units, both mean professional experience and tenure were high. Presumably, more experienced RNs are more skilled at detecting warning symptoms and making clinical decisions, and would therefore contribute more effectively to fall risk assessment and intervention planning. However, as our sample hospital's fall prevention program and their nurses' adherence to them were beyond the scope of the current study, the interpretation of these findings is speculative.

To our knowledge, the current study is the first to explore possible relationships between patient turnover and either falls or injurious falls. While our unit-level analysis indicated no correlations, shift-level data might have yielded different results, as admissions and discharges may have concentrated disproportionately on a single shift. Patrician et $a l .{ }^{[20]}$ noted that higher shift patient censuses were related to higher fall rates. Our sample's relatively high nurse staffing levels and RN professional experience might have mitigated the possible negative effects of high turnover rates.

In our sample the safety climate varied between units, indicating that there were differences concerning the clinicians' awareness of unsafe practices, lack of support for safety efforts and the possibility to discuss and to learn from errors. In the regression model, safety climate proofed to have a strong association with inpatient falls as shown in previous studies. ${ }^{[30,31]}$ However, the protective effect of a strong safety climate disappeared when controlled for the nursing time of care, our proxy for patient complexity. Complex patient situations requiring a great amount of nursing time might be prone to imbalances in the nursing process of care which may result in omitting required nursing interventions or leav- 
ing interventions uncompleted, which has been shown to be a more significant factor than safety climate. ${ }^{[32]}$ Kalisch, Tschannen and Hee Lee ${ }^{[12]}$ found missed nursing care to be an important moderator for fall rates. The effect of staffing levels was lessened when nursing care was completed, especially ambulation, patient assessment in each shift, call light response and toilet assistance. ${ }^{[12]}$

The current study is subject to several limitations such as its observational design, a small sample size, including only one hospital setting, and a relatively short observation period. Furthermore, the secondary characteristics of our analysis prevented inclusion of important control variables, e.g. the hospital's fall prevention program and its success level, and we did not measure how appropriate and consistent procedures concerning patient admissions, discharges and transfers in our sample were. Fall data were based entirely on nurse reports. Notwithstanding these limitations, this study's findings suggest that nurses' professional experience and nurse-reported safety climate are important factors concerning in-patient falls. Our sample units' favorable nurse staffing and RN experience levels may have contributed to staff perceptions of a positive safety climate. However, while patientto-nurse ratios and skill mixes were favorable on all units, safety climate responses varied.

\section{Conclusion}

By linking nurse staffing variables to in-patient falls and fall injuries, the current study's findings partly confirm those of previous research. Further investigation will be necessary to isolate key factors influencing the association at the unit level between safety climate and in-patient falls. To understand the missing links between nurse staffing variables, other system factors and in-patient falls, we recommend a prospective unit-level study, possibly using a mixed-methods design. Our finding that nurses' professional experience correlates significantly with in-patient falls is potentially valuable for nurse managers. For clinical practice, in light of the severe burdens injurious falls involve for both patients and hospitals, we recommend focusing on fall prevention strategies along with monitoring safety climate and nurse staffing levels.

\section{REFERENCES}

[1] Bouldin E, et al. Falls Among Adult Patients Hospitalized in the United States: Prevalence and Trends. Journal of Patient Safety. 2013; 9(1): 13-17. PMid: 23143749.

[2] Murray G, Cameron I, Cumming R. The Consequences of Falls in Acute and Subacute Hospitals in Australia That Cause Proximal Femoral Fractures. Journal of the American Geriatrics Society. 2007; 55(4): 577-582. PMid: 17397437. http://dx.doi.org/10.1111 $/ j .1532-5415.2007 .01102 \cdot x$

[3] Brand C, Sundararajan V. A 10-year cohort study of the burden and risk of in-hospital falls and fractures using routinly collected hospital data. Quality \& Safety in Health Care. 2010; 19(6): e51. PMid: 20558479.

[4] Heinrich S, et al. Cost of falls in old age: a systematic review. Osteoporos International. 2010; 21: 891-902. PMid:19924496. http: //dx.doi.org/10.1007/s00198-009-1100-1

[5] Cameron I, et al. Interventions for preventing falls in older people in care facilities and hospitals. Cochrane database of systematic reviews. 2012(12).

[6] American Geriatrics Society and British Geriatrics Society, Summary of the Updated American Geriatrics/British Geriatrics Society Clinical Practice Guideline for Prevention of Falls in Older People. Journal of the American Geriatrics Society. 2011; 59(1): 148-157. PMid: 21226685. http://dx.doi.org/10.1111/j.1532-5415. $2010.03234 . x$

[7] Krauss MJ, et al. Intervention to prevent falls on the medical service in a teaching hospital. Infection Control and Hospital Epidemiology. 2008; 29(6): 539-545. PMid: 18476777. http://dx.doi.org/10. $1086 / 588222$

[8] Oliver D, et al. Strategies to prevent falls and fractures in hospitals and care homes and effect of cognitive impairment: systematic review and meta-analyses. British Medical Journal. 2007; 334(7584): 82.
PMid: 17158580.http://dx.doi.org/10.1136/bmj.39049.7 06493.55

[9] Schwendimann R, et al. Falls and consequent injuries in hospitalized patients: effects of an interdisciplinary falls prevention program. BMC Health Services Research. 2006; 7(6): 69. PMid: 16759386. http://dx.doi.org/10.1186/1472-6963-6-69

[10] Cameron I, et al. Interventions for preventing falls in older people in nursing care facilities and hospitals. Cochrane database of systematic reviews. 2010; 2010(1). PMid: 20091578. http://dx.doi.org/1 $0.1002 / 14651858$. CD005465.pub2

[11] Coussement J, et al. Preventing Falls in Hospitals: Interpreting the evidence. Journal of the American Geriatrics Society. 2008; 56(9): 1775-1776. http://dx.doi.org/10.1111/j.1532-5415. 2008 $.01835 . x$

[12] Kalisch B, Tschannen D, Hee Lee K. Missed Nursing Care, Staffing, and Patient Falls. Journal of Nursing Care Quality. 2012; 27(1): 6-12. PMid: 21738057. http://dx.doi.org/10.1097/NCQ.0b013e3 18225aa23

[13] Kalisch B, Tschannen D, Hee Lee K. Do staffing levels predict missed nursing care? International Journal for Quality in Health Care. 2011; 23(3): 302-308. PMid: 21486856. http://dx.doi.org/10.1093 /intqhc/mzr009

[14] Dunton N, et al. The relationship of nursing workforce characteristics to patient outcomes. Online Journal of Issues in Nursing. 2007; 12(3):

[15] Lake ET, et al. Patient falls: Association with hospital Magnet status and nursing unit staffing. Research in Nursing \& Health. 2010; 33(4): 413-425. PMid: 20824686. http://dx.doi.org/10.1002/nur .20399

[16] Titler MG, et al. Factors associated with falls during hospitalization in an older adult population. Research and Theory for Nursing Prac- 
tice. 2011; 25(2): 127-148. PMid: 21696092. http://dx.doi.org $/ 10.1891 / 1541-6577.25 .2 .127$

[17] Mark BA, Salyer J, Wan TTH. Professional Nursing Practice. Impact on Organizational and Patient Outcomes. JONA. 2003; 33(4): 224-234. http://dx.doi.org/10.1097/00005110-200 304000-00008

[18] Donaldson N, et al. Impact of California's licensed nurse-patient ratios on unit-level nurse staffing and patient outcomes. Policy, Politics \& Nursing Practice. 2005; 6(3): 198. PMid: 16443975. http://dx.doi.org/10.1177/1527154405280107

[19] Tzeng HM, Mei Hu H, Yin CY. The Relationship of the Hospital Acquired Injurious Fall Rates with the Quality Profile of a Hospital's Care Delivery and Nursing Staff Patterns. Nursing economic. 2011; 29(6): 299-316. PMid: 22360104.

[20] Patrician P, et al. The Association of Shift-Level Nurse Staffing With Adverse Patient Events. The Journal of nursing administration. 2011; 41(2): 64-70. PMid: 21266884. http://dx.doi.org/10.1097/N NA. Ob013e31820594bf

[21] Institute of Medicine. Patient Safety. Achieving a new standard of care, in Q.C. series. Washington D.C.: The National Academies Press; 2004.

[22] Myny D, et al. Determining a set of measurable and relevant factors affecting nursing workload in the acute care hospital setting: A cross-sectional study. International Journal of Nursing Studies. 2012; 49(4): 427-436. PMid: 22030021. http://dx.doi.org/10.1016 /j.ijnurstu.2011.10.005

[23] Jacobson AK, Seltzer JE, Dam EJ. New methodology for analyzing fluctuating unit activity. Nursing Economics. 1999; 17(1): 55-59. PMid: 10335224.

[24] Storrer Brown D, et al. Nursing-sensitive benchmarks for hospitals to gauge high-reliability performance. Journal for healthcare quality : official publication of the National Association for Healthcare Quality. 2010; 32(6): 9-17. PMid: 20946421. http://dx.doi.org/10. 1111/j.1945-1474.2010.00083.x

[25] Unruh L, Fottler M. Patient turnover and nursing staff adequacy. Health Services Research. 2006; 41(2): 599-612. PMid: 16584467. http://dx.doi.org/10.1111/j.1475-6773.2005.00496.x

[26] Needleman J, et al. Nurse staffing and inpatient hospital mortality. The New England Journal of Medicine. 2011; 364(11): 1037-1045. PMid: 21410372. http://dx.doi.org/10.1056/NEJMsa10010 25

[27] Park S, et al. Patient Turnover and the Relationship Between Nurse Staffing and Patient Outcomes. Research in Nursing \& Health. 2012; 35: 277-288. PMid: 22457013. http://dx.doi.org/10.1002/n ur. 21474

[28] Sexton JB, Berenholth SM, Goeschel CA, et al. Assessing and improving safety climate in a large cohort of intensive care units. Critical Care Medicine. 2011; 5(39): 934-939. PMid: 21297460. http://dx.doi.org/10.1097/CCM.0b013e318206d26c

[29] Mark B, et al. Exploring Organizational Context and Structure as Predictors of Medication Errors and Patient Falls. Journal of Patient
Safety. 2008; 4(2): 66-77. http://dx.doi.org/10.1097/PTS.0 b013e3181695671

[30] Vogus T, Sutcliff K. The Safety Organizing Scale. Development and Validation of a Behavioral Measure of Safety Culture in Hospital Nursing Units. Medical Care. 2007; 45(1): 47-54. http: //dx.doi.org/10.1097/01.mlr.0000244635.61178.7a

[31] Taylor JA, et al. Do nurse and patient injuries share common antecedents? An analysis of associations with safety climate and working conditions. BMJ Quality \& Safety. 2012; 21(2): 101-111. PMid: 22016377. http://dx.doi.org/10.1136/bmjqs-2011-00008 2

[32] Ausserhofer D, et al. The association of patient safety climate and nurse-related organizational factors with selected patient outcomes: A cross-sectional survey. International journal of nursing studies. 2013; 50(2): 240-252. PMid: 22560562. http://dx.doi.org/10. 1016/j.ijnurstu. 2012.04.007

[33] Aiken L, Clarke S, Sloane D. Hospital Staffing, Organization, and Quality of Care: Cross-National Findings. Nursing Outlook. 2002; 50: 187-194. PMid: 12386653. http://dx.doi.org/10.1067/m no. 2002.126696

[34] Pronovost P, et al. Framework for Patient Safety Research and Improvement. Circulation. 2009; 119: 330-337. PMid: 19153284. ht tp://dx.doi.org/10.1161/CIRCULATIONAHA.107.729848

[35] Sexton J, et al. The Safety Attitudes Questionnaire: psychometric properties, benchmarking data, and emerging research. BMC Health Services Research. 2006; 6(44). PMid: 16584553.

[36] Devriendt E, et al. Content validity and internal consistency of the Dutch Translation of the Safety Attitudes Questionnaire: an observational study. International journal of nursing studies. 2012; 49(3): 327-337. PMid: 22035966. http://dx.doi.org/10.1016/j.i jnurstu.2011.10.002

[37] Zimmermann N, et al. Assessing the safety attitudes questionnaire (SAQ), German language version in Swiss university hospitals - a validation study. BMC health services research. 2013; 13. http://dx.doi.org/10.1186/1472-6963-13-347

[38] Lamb S, et al. Development of a common outcome data set for fall injury prevention trials: the prevention of falls network europe consensus. Journal of the American Geriatrics Society. 2005; 53(9): 1618-1622. PMid: 16137297. http://dx.doi.org/10.1111/j $.1532-5415.2005 .53455 . x$

[39] Schwendimann R, et al. Characteristics of hospital inpatient falls across clinical departments. Gerontology. 2008; 54(6): 342-348. PMid: 18460867. http://dx.doi.org/10.1159/000129954

[40] Krauss M, et al. A Case-control Study of Patient, Medication, and Care-related Risk Factors for Inpatient Falls. Journal of general internal medicine. 2005; 20: 116-122. PMid: 15836543. http: //dx.doi.org/10.1111/j.1525-1497.2005.40171.x

[41] McGillis Hall L, Doran D, Pink G. Nurse Staffing Models, Nursing Hours, and Patient Safety Outcomes. Journal of Nursing Administration. 2004; 34(1): 41-45. PMid: 14737034. http://dx.doi.org /10.1097/00005110-200401000-00009 